\title{
A COMPARATIVE STUDY OF CARRIER STATE OF CANDIDA AND ITS SPE- CIATION IN ORAL FLORA - AMONG HEALTHY INDIVIDUALS, PERSONS WITH DM AND HIV SERO POSITIVE INDIVIDUALS
}

\author{
by M. Bharathi, Anaparthy Usha Rani, Cautha Sandhya
}

comment:
Giulio Fortuna DMD, PhD, Annamaria Pollio DMD

Our Dermatol Online. 2012; 3(2): 107-108

Date of submission: 20.02.2012 / acceptance: 20.02.2012

Conflicts of interest: None

Fungi are important agents of human disease. The genus Candida gathers the most important fungal pathogens. They can cause a wide range of human diseases from superficial mucosal infections to life-threatening invasive infections. Normally, fungi are saprophitic residents of oral mucosa and the $40-60 \%$ of healthy adults harbour commensal Candida in their mouth without signs and symptoms of candidiasis [1]. The most common cause of oropharyngeal candidiasis is the polymorphic species Candida albicans. Candida dubliensis was identified in the Irish HIV infected and AIDS population in the early 1990s [2]. There are many phenotypic similarities between Candida albicans and Candida dubliensis that pose the problems in their identification and previously led to misidentification of these two species. Epidemiological studies have shown that Candida dubliensis is prevalent throughout the world and it is associated with oropharyngeal infections in patients with human immunodeficiency virus (HIV) virus [3].

Data acquired from its isolation in healthy and immunocompromised patients are variable and there is no still consensus on the epidemiological relevance of this species. It has been reported that non controlled glycemia predisposes to oral candidiasis in diabetic patients and the density of Candida growth is increased in patients with diabetes mellitus. The mechanism by which the diabetes predisposes to high oral concentration of Candida has not yet been established [1]. The Bharathi et al.'s [4] study is an interesting investigation which underlines the higher percentage of asymptomatic oral carriage of Candida in HIV-positive patients (54\%) versus diabetic patients $(44 \%)$ and healthy individuals (24\%). These results confirm those ones from previous investigations [5-6], but interestingly the percentage of HIV-positive patients seems to be higher only in those individuals with a very low blood cell CD4+ count [7-8]. However, there's an increasing need of further longterm longitudinal epidemiological studies worldwide in order to better establish the real incidence and prevalence of asymptomatic oral carriage of Candida in these three categories of patients, and ascertain whether or not race, sex, and age, other than immunocompentent status, might have any influence on carrier state. With these epidemiological data, we may try to prove conclusively whether or not there is any tight relationship between diabetes, HIV-positive status and oral carriage of Candida, who really runs a higher risk of developing such infections, how many of them develop candidiasis and why, and, last but not less important, whether or not any preventive treatment might be of some benefit.

\section{REFERENCES}

1. Soysa NS, Samaranayake LP, Ellepola NB: Diabetes mellitus as a contributory factor in oral candidosis. Diabet Med. 2006; 23: 455-459.

2. Loreto ES, Scheid LA, Nogueira CW, Zeni G, Santurio JM, Alves SH: Candida Dubliensis : Epidemiology and phenotipic methods for identification. Mycopathologia. 2010; 169: 431-433.

3. Sullivan DJ, Moran GP, Pinjon E, Al-Mosaid A, Stokes C, Vaughan C, et al: Comparison of the epidemiology, drug resistence mechanisms, and virulence of Candida Dublinensis and Candida Albicans. FEMS Yeast Research. 2004; 4: 369-376.

4. Bharathi M, Usha Rani A, Sandhya C: A comparative study of carrier state of candida and its speciation in oral flora - among healthy individuals, persons with DM and HIV sero positive individuals. Our Dermatol Online. 2012; 3: 102-106.

5. Campisi G, Pizzo G, Milici ME, Mancuso S, Margiotta $\mathrm{V}$ : Candidal carriage in the oral cavity of human immunodeficiency virus-infected subjects. Oral Surg Oral Med Oral Pathol Oral Radiol Endod. 2002; 93: 281-286.

6. Al-Attas SA, Amro SO: Candidal colonization, strain diversity, and antifungal susceptibility among adult diabetic patients. Ann Saudi Med. 2010; 30: 101-108.- 
7. Liu X, Liu H, Guo Z, Luan W: Association of asymptomatic oral candidal carriage, oral candidiasis and CD4 lymphocyte count in HIV-positive patients in China. Oral Dis. 2006; 12: 41-44.

8. Fong IW, Laurel M, Burford-Mason A: Asymptomatic oral carriage of Candida albicans in patients with HIV infection. Clin Invest Med. 1997; 20: 85-93.

\section{Correspondence:}

Giulio Fortuna, DMD, PhD

Oral Medicine Unit

Department of Head and Neck Surgery

Ascalesi Hospital

Via Egiziaca a Forcella, 3180139 Naples (Italy)

Phone: (+39) 81254.2134

Fax:(+39) 81254.2191

E-mai: giulio.fortuna@gmail.com 